\title{
The Applicability of the Efficient Market Hypothesis In Emerging Markets
}

\author{
Doaa El-Diftar \\ Lecturer in Finance \\ College of Management \& Technology (CMT) \\ Department of Finance \\ Arab Academy for Science, \\ Technology and Maritime Transport \\ Cairo, Egypt \\ doaaeldiftar@aast.edu
}

\begin{abstract}
The efficient market hypothesis is highly controversial and often its validity is disputed. So, this research aims to explore the legitimacy of the efficient market hypothesis in nine emerging markets. The research is conducted on daily returns from nine major emerging markets indices from 2015 to 2020. This study tests the weak-form efficiency by employing both parametric and non-parametric statistical techniques. The results of these tests show that stock markets in the tested emerging markets do not follow a random walk, hence are not weakly efficient. However, the results also reveal that Turkey, Thailand, Indonesia, Brazil, and India are moving towards attaining weak-form efficiency in comparison with Mexico, Saudi Arabia, Egypt, and Pakistan, who lag behind. Overall, the outcomes of this research show that the tested markets are not efficient, hence, investors may take advantage of these markets in generating tremendous profits. But they also show that there are variations of efficiency and that some of these markets are closer to being efficient and less predictable than others. This research may be of interest to market regulators in conducting financial reforms to reduce corruption and information asymmetries as an attempt to becoming more efficient.
\end{abstract}

Keywords: Efficient market hypothesis, Market efficiency, Random-walk theory, Weak-form efficiency, Emerging markets.

\section{Introduction}

Information efficiency refers to how quicky prices are adjusted to all available information. In a fully efficient market, forecasting changes in stock prices should not be possible. This is because the efficient market hypothesis (EMH) assumes that all relevant information as well as investors' expectations are already incorporated into actual prices (Aktan et al., 2018). So, this means that in an efficient market, stock prices should be unpredictable and random. This notion is popularly known as the random-walk hypothesis. If this holds, then it can be concluded that investors cannot make substantial gains without taking substantial risks and technical analysis will be no good (Atkan et al., 2018).

The main cause of price change is the arrival of new information and since the $\mathrm{EMH}$ proposes that in efficient markets prices are quickly adjusted to all new information; there will be no reason for investors to believe prices are greatly over or under valued, hence, they will not be able to make substantial profits. Basically, the EMH implies that prices are fairly priced and that you should trust the market that what you pay for is what you

* This article was submitted in August 2021, and accepted for publishing in September 2021.

(c) Arab Administrative Development Organization- League of Arab States, 2024, pp 227-235، D DOI: 10.21608/aja.2021.89040.1130 
get (Clarke et al., 2001). This is why any change in stock prices should be random and unpredictable or as what is referred to earlier as following a random-walk.

Numerous studies, mostly in developed economies, have been conducted in order to validate the essence of the EMH. This research, on the other hand, concentrates on emerging markets from diverse locations, which is important in narrowing the research gap in this area. Also, many emerging markets are considered very attractive to investors in making great profits. This study examines the weak-from efficiency in nine emerging markets. The findings will reveal whether these markets are efficient or not and which if any is closer to attaining market efficiency.

The remainder of the paper will be structured as follows. The next section provides the theoretical framework of the study followed the literature review and development of hypotheses. A description of the research methods is presented in section four followed by the results and discussion. The conclusion, limitations and recommendations are presented in the final section of the paper.

\section{Theoretical Framework}

There are three forms of the EMH (market efficiency), they are the weak, semi-strong, and strong. The weak form just deals with past information meaning that it assumes that prices are adjusted to all available past information such as historical prices or returns (Chaibi, 2014). So, as was mentioned earlier, investors will not be able to forecast prices since all available past information should already be incorporated into stock prices (Aktan et al. 2018). The weak form of EMH assumes that no one can detect mis-priced securities or make a profit by just analyzing past prices or financial information that are already available to the public.

The semi-strong form does not deal with just past information but with all publicly available information. Semi-strong efficiency assumes that prices will quickly be adjusted to any information that is publicly revealed or published (Chaibi, 2014; Aktan et al. 2018). This includes any kind of information and not just restricted to financial information. This again implies that investors cannot make substantial gains from any kind of public information since it is already revealed to everyone. The semi-strong is much stronger than the weak form since it is very difficult and costly for someone to collect and process all publicly available information (Clarke et al., 2001).

The strictest form of efficiency is the strong form which assumes that prices are not just adjusted according to all past and publicly available information, but also according to private information or what is known as insider information (Gupta and Yang, 2011; Chaibi, 2014; Aktan et al. 2018). This implies that even insiders will not be able to make profits or beat the market using their insider information.

As explained, the EMH and the random walk theory propose that investors in efficient markets cannot beat the market with the information they have, but they can beat the market by chance or randomly (Clarke et al., 2001). In order for the random walk to hold, successive prices should be independent of one another (Cooray and Wickremasinghe, 2007; Malafeyev et al., 2017). This is because in well-functioning developed economies, arbitrageurs will quickly eliminate any persistent pattern in prices thus making it impossible to predict future price movements (Howrey, 1965).

Emerging markets are less efficient than developed and this may be because they do not have many reliable financial intermediaries in comparison with developed countries as well as poor corporate governance (Oprean, 2012). Also, emerging markets tend to have more unreliable information as well as great market volatility (Alam et al., 2007). But still many investors may find emerging markets more attractive and profitable for investment since they can forecast or speculate changes in stock prices and make tremendous gains (Aktan et al., 2018). This is because in inefficient markets, investors may use publicly available information that is ignored by the market and make abnormal returns (Alam et al., 2007). So, it has to be taken into account that this information inefficiency can be a sign of many unexploited opportunities that very 
smart investors can take advantage of. This is why continuous research in emerging markets is essential to better understand them.

It is very hard and even impossible for markets to be strongly or perfectly efficient. But what differentiates developed from emerging is that many studies found that many emerging markets tend not to fall under any form of efficiency. Since there is still a gap in research regarding studies done on emerging markets, this study will concentrate on emerging markets from different parts of the world.

With regards to this study, the focus will be on the weak form of efficiency. Since the weak form of efficiency assumes that all past market prices are fully reflected in present prices then returns should be random or follow a random walk. Basically, in order for a market to be weakly efficient, it should not be possible for investors to predict stock prices based on their historical returns. The random walk is the core of the weak-form efficiency and thus testing it will be the focus of this study. Since, less developed countries may not even be weakly efficient, it is logical and more convenient to test the weak-form efficiency first rather than the semi-strong or strong.

\section{Literature Review and Development of Hypotheses}

This part of the research will contain the outcomes of past studies on the EMH with concentration on studies applied in emerging markets. Then the section will be concluded with the research hypotheses.

While conducting their study on emerging markets from the Middle East, Omran and Farrar (2006) rejected the random walk hypothesis and found that stock returns in these markets show calendar effects. Kamal (2014) also rejected the weak-form efficiency when she applied her study on the Egyptian Stock Market before and after the $25^{\text {th }}$ of January revolution.

Lagoarde-Segot and Lucey (2008) have also conducted their study in the MENA region on seven different markets: Egypt; Israel; Jordan; Lebanon; Morocco; Tunisia; Turkey. By constructing an efficiency index for each market, they found that among the seven tested markets, Turkey and Israel showed the strongest evidence of weak-form efficiency. They contributed this to their greater liquidity, stock market capitalization, as well as having more developed financial systems.

Simons and Laryea (2005) applied their study in many stock markets in Africa and found that with the exception of South Africa, all tested stock markets were weak form inefficient. Still in Africa, Ayentimi et al. (2013) also rejected the weak form efficiency when they applied their study in the Ghanaian Stock Exchange. They found that stock returns showed volatility clustering; thus, contradicting random walk. They also found that stock returns exhibited a non-normal distribution.

When testing for weak-form efficiency in India, Poshakwale (2002) found that daily returns do not follow a random walk and exhibit a non-linear dependence. Also, the results generated by Gupta and Yang (2011) were similar when they applied their study on both the Mumbai Stock Exchange and National Stock Exchange of India. When they used the Augmented Dickey Fuller test, they found that both markets are not weak-form efficient under daily, weekly and monthly data. Lastly, with regards to the Indian market, Malafeyev et al. (2017) also find that the Indian Stock Market does not exhibit weak-form efficiency and does not follow a random walk but is gradually moving towards following a random-walk in comparison with the Chinese market.

The results generated by Alam el al. (2007) and by Mobarek and Keasey (2000) were consistent with this when they applied their study in Bangladesh. They rejected the weak-form efficiency and the random walk hypothesis when they applied their study on daily prices indices of all securities listed in Dhaka Stock Market.

Nisar and Hanif (2012) also rejected the weak form efficiency in four South Asian Markets: India; Pakistan; Bangladesh; Sri Lanka. They suggested that none of these markets are weak-form efficient and that stock 
prices do not follow a random walk. On the contrary, Cooray and Wickremasinghe (2007) supported the weakform efficiency in India, Sri Lanka, and Pakistan and concluded that these markets follow a random walk.

When the validity of the weak form efficiency was tested in Hong Kong; Chaibi's (2014) results rejected the random walk and concluded that stock markets in Hong Kong are not efficient. Chaibi's (2014) results also rejected normality pertaining to the distribution of the tested indices.

The results by Worthington and Higgs (2004) showed that European emerging markets with the exception of Haungry rejected the presence of random walk and weak form efficiency. Consistent with this, Nurunnabi (2012) also concluded that in general emerging markets were found to not follow a random walk and hence are inefficient.

From understanding the essence of the $\mathrm{EMH}$ and the literature pertaining to it; the following research hypotheses are developed to test the weak-form efficiency.

First null hypothesis tests for normality:

- HOa:The daily market returns in emerging markets are normally distributed.

- H1a: The daily market returns in emerging markets are not normally distributed.

Second null hypothesis tests the randomness of returns:

- HOb: The daily market returns in emerging markets follow a random walk.

- $\quad H 1 b$ : The daily market returns in emerging markets do not follow a random walk.

\section{Research Methods}

\section{Sample:}

The sample included nine emerging market indices and they are NIFTY 50 from India; IPC Index from Mexico; Karachi 100 from Pakistan; TASI from Saudi Arabia; BIST 100 from Turkey; EGX100 from Egypt; IDX Kompas 100 from Indonesia; Bovespa Brazil 50 from Brazil; SET 100 from Thailand. The study used one of the largest market indices for each country rather than individual stock data covering from January 2015 to January 2020.

\section{Tested Variable:}

The daily market returns were used for all tested indices and are calculated from their daily market prices as follows:

$$
R_{t}=\ln \left(P_{t} / P_{t-1}\right)
$$

where

$$
\begin{array}{ll}
\mathrm{R}_{\mathrm{t}}=\text { market return for period } \mathrm{t} & \mathrm{P}_{\mathrm{t}}=\text { market price index for period } \mathrm{t} \\
\mathrm{P}_{\mathrm{t}-1}=\text { market price index for period } \mathrm{t}-1 & \mathrm{Ln}=\text { natural } \log
\end{array}
$$

\section{Statistical Tests:}

The study employed both parametric and non-parametric techniques to test for normality as well as weak form efficiency in each market. The parametric tests are skewness, kurtosis, Jarque-Bera, Autoregression models and Augmented Dickey-Fuller unit root test. The results are reinforced by the non-parametric tests which are the One-Sample Kolmogorov-Smirniv test, Phillips-Perron unit root test and run tests.

For preliminary analyses, the descriptive statistics will be computed for all indices including the Skewness, Kurtosis and Jarque-Bera tests. The results of these tests will show whether the data exhibit a normal distribution. In order to validate the weak form efficiency, there should be no correlation of price movements over time. Therefore, the following two tests will be applied: autocorrelation models to test whether stock price movement for one period of time is related to the price movements in a previous 
period; the augmented dickey-fuller test, which is the most widely used method for testing the stationary of a series.

To further reinforce the results, non-parametric tests will be applied. First, the one-sample Kolmogorov-smirniv test is applied to test whether the data comes from a normal distribution. Then as an alternative test to autocorrelation, a run test will be used which will look at the changes in price through time and compares the actual changes to what would be expected for a random series. Along with augmented dickey-fuller test (ADF), Phillips-Perron (PP) non-parametric unit root test will be run to further test the stationary of the series.

Both the ADF and PP will test the null hypothesis of $\mathrm{R}_{\mathrm{t}}$ is a random walk or a unit root, with $\mathrm{c}$ being the constant and $\varepsilon_{t}$ being the stationary process as follows:

$$
\mathrm{R}_{\mathrm{t}}=\mathrm{c}+\mathrm{R}_{\mathrm{t}-1}+\varepsilon_{\mathrm{t}}
$$

ADF will test the null hypothesis of random walk against a stationary alternative as follows:

$$
\Delta \mathrm{R}_{\mathrm{t}}=\mathrm{C}+\alpha \mathrm{R}_{\mathrm{t}-1}+\sum_{\mathrm{i}=1}^{\mathrm{n}} \phi \mathrm{i} \Delta \mathrm{R}_{\mathrm{t}-1}+\varepsilon_{\mathrm{t}}
$$

$\Delta \mathrm{R}_{\mathrm{t}-1} \rightarrow \mathrm{n}$ extra regressors added to eliminate possible problems caused by serial correlations in the error terms.

The difference in the PP unit root test is that the extra regressors $\Delta \mathrm{R}_{\mathrm{t}-\mathrm{i}}$ are not included in the regression and the serial correlation of the residuals is corrected via a non-parametric method.

For a robustness check, Zivot-Andrews unit root test will be applied in order to take into account any structural breaks in the date. The ADF and PP unit root tests assume data are without structural breaks, while on the other hand the Zivot-Andrews unit root test assumes a single break. So, it pivotal to perform a unit root test that incorporated structural breaks in order to strengthen the results.

\section{Results and Discussion}

Table I provides the descriptive statistics for all the tested market indices. As shown in the results, with the exception of Indonesia's stock index, all tested market indices are skewed to the left. Kurtosis values are high for all indices further indicating a deviation from normality. These results are further backed up by the results of the Jarque-Bera test. The results of the Jarque-Bera test are high and highly significant for all tested indices indicating that returns do not exhibit a normal distribution.

\begin{tabular}{|c|c|c|c|c|c|c|c|c|c|}
\hline & $\begin{array}{l}\text { BIST_100 } \\
\text { (Turkey) }\end{array}$ & $\begin{array}{c}\text { BOVESPA } \\
\text { BRAZIL_50 } \\
\text { (Brazil) }\end{array}$ & $\begin{array}{l}\text { EGX100 } \\
\text { (Egypt) }\end{array}$ & $\begin{array}{c}\text { IDX_KOM- } \\
\text { PAS_100 } \\
\text { (Indonesia) }\end{array}$ & $\begin{array}{c}\text { IPC_INDEX } \\
\text { (Mexico) }\end{array}$ & $\begin{array}{c}\text { KARA- } \\
\text { CHI_100 } \\
\text { (Pakistan) }\end{array}$ & $\begin{array}{l}\text { NIFTY50 } \\
\text { (India) }\end{array}$ & $\begin{array}{l}\text { SET_100 } \\
\text { (Thailand) }\end{array}$ & $\begin{array}{c}\text { TASI } \\
\text { (Saudi } \\
\text { Arabia) }\end{array}$ \\
\hline Mean & 0.0002 & 0.0007 & 0.0002 & -0.0001 & 0.00003 & 0.0002 & 0.0003 & 0.0001 & -0.000005 \\
\hline Median & 0.0006 & 0.0007 & 0.0004 & -0.0007 & 0.0001 & 0.0002 & 0.0004 & 0.0002 & 0.0004 \\
\hline Maximum & 0.0526 & 0.0625 & 0.0627 & 0.0503 & 0.0337 & 0.0442 & 0.0518 & 0.0432 & 0.0712 \\
\hline Minimum & -0.0735 & -0.0916 & -0.0585 & -0.0575 & -0.0599 & -0.0477 & -0.0610 & -0.0526 & -0.0710 \\
\hline Std. Dev. & 0.0129 & 0.0137 & 0.0101 & 0.0108 & 0.0085 & 0.0102 & 0.0086 & 0.0083 & 0.0110 \\
\hline Skewness & -0.4006 & -0.1960 & -0.2448 & 0.3174 & -0.4878 & -0.2004 & -0.2514 & -0.1938 & -0.4554 \\
\hline Kurtosis & 5.0844 & 5.2638 & 7.2964 & 5.7079 & 6.9359 & 4.9436 & 6.7631 & 6.0367 & 8.9017 \\
\hline Jarque-Bera & 260.95 & 273.81 & 948.95 & 390.64 & 859.83 & 203.31 & 740.51 & 476.01 & 1855.76 \\
\hline Probability & 0.0000 & 0.0000 & 0.0000 & 0.0000 & 0.0000 & 0.0000 & 0.0000 & 0.0000 & 0.0000 \\
\hline$N$ & 1256 & 1245 & 1218 & 1212 & 1255 & 1239 & 1233 & 1219 & 1249 \\
\hline
\end{tabular}

Table I: Descriptive Statistics

Note: Table I Presents the Descriptive Statistics for the Daily Market returns of the Nine Tested Market Indices. 
From the results of the non-parametric one-sample Kolmogorov-smirniv test in Table II, it can be noted that the null hypothesis is rejected for all tested indices. These outcomes are consistent with the results generated by the descriptive statistics that returns for all tested indices do not exhibit a normal distribution. So, regarding normality HOa is rejected and H1a is accepted which is that the daily market returns in emerging markets are not normally distributed. These results are coherent with the results generated by many studies applied on emerging markets (e.g., Ayentimi et al., 2013; Chaibi, 2014).

In order to test the second hypothesis on whether market returns follow a random walk or not, hence confirming the weak form efficiency, the next parametric and non-parametric tests are performed. First, the results of the parametric ADF test and the autoregression models are presented and backed up by the non-parametric run tests.

The null hypothesis in the augmented-dickey fuller is that the tested series are non-stationary or contain a unit root. As evident by the results in Table III, the ADF test statistic is highly significant, leading to the rejection of the null hypothesis. Also, as provided in Table 3, the results of PP non-parametric unit root test reinforce ADF test's results. So, from these results, it can be concluded that daily market returns are stationary or do not follow a random walk, and hence, rejecting the weak form efficiency. The results of ADF test are consistent with the results generated by many academics (e.g., Gupta and Yang, 2011; Nisar and Hanif, 2012; Kamal, 2014).

Table IV provides for the results for the auto regression models testing
Table II: One-Sample Kolmogorov-Smirniv Test

\begin{tabular}{cccccc}
\hline Index (Market) & Absolute Positive Negative & Kolmogorov- & Asymp. \\
Smirniv Z & Sig. \\
\hline NIFTY50 (India) & 0.048 & 0.041 & -0.048 & 0.048 & 0.000 \\
\hline IPC Index (Mexico) & 0.045 & 0.037 & -0.045 & 0.045 & 0.000 \\
\hline $\begin{array}{c}\text { Karachi 100 } \\
\text { (Pakistan) }\end{array}$ & 0.058 & 0.041 & -0.058 & 0.058 & 0.000 \\
\hline TASI (Saudi Arabia) & 0.076 & 0.060 & -0.076 & 0.076 & 0.000 \\
\hline BIST 100 (Turkey) & 0.040 & 0.034 & -0.040 & 0.040 & 0.000 \\
\hline EGX100 (Egypt) & 0.068 & 0.059 & -0.068 & 0.068 & 0.000 \\
\hline $\begin{array}{c}\text { IDX Kompas 100 } \\
\text { (Indonesia) }\end{array}$ & 0.057 & 0.057 & -0.046 & 0.057 & 0.000 \\
\hline $\begin{array}{c}\text { Bovespa Brazil 50 } \\
\text { (Brazil) }\end{array}$ & 0.037 & 0.037 & -0.036 & 0.037 & 0.000 \\
\hline $\begin{array}{c}\text { SET 100 (Thailand) } \\
\text { 100 }\end{array}$ & 0.052 & 0.048 & -0.052 & 0.052 & 0.000 \\
\hline
\end{tabular}

Note: Table Il tests the null hypothesis that the distribution of the data is normal with mean 0.000 and standard deviation 0.01 .

\section{Table III: ADF and PP Unit Root Tests}

\begin{tabular}{ccccc}
\hline Index (Market) & ADF test statistic P-value & PP test statistic & P-value \\
\hline NIFTY50 (India) & -19.3125 & 0.0000 & -33.1543 & 0.0000 \\
\hline IPC Index (Mexico) & -16.4177 & 0.0000 & -32.0099 & 0.0000 \\
\hline $\begin{array}{c}\text { Karachi 100 } \\
\text { (Pakistan) }\end{array}$ & -19.4077 & 0.0000 & -29.7602 & 0.0000 \\
\hline TASI (Saudi Arabia) & -17.3684 & 0.0000 & -30.8874 & 0.0000 \\
\hline BIST 100 (Turkey) & -17.7937 & 0.0000 & -34.8630 & 0.0000 \\
\hline EGX100 (Egypt) & -18.7626 & 0.0000 & -27.0770 & 0.0000 \\
\hline $\begin{array}{c}\text { IDX Kompas 100 } \\
\text { (Indonesia) }\end{array}$ & -17.7675 & 0.0000 & -34.1102 & 0.0000 \\
\hline $\begin{array}{c}\text { Bovespa Brazil 50 } \\
\text { (Brazil) }\end{array}$ & -18.1531 & 0.0000 & -35.4104 & 0.0000 \\
\hline SET 100 (Thailand) & -15.9820 & 0.0000 & -34.3229 & 0.0000 \\
\hline
\end{tabular}

Note: Table III presents the results of the parametric Augmented Dickey-Fuller (ADF) test and the non-parametric Phillips-Perron (PP) test which test the null hypothesis that the series are non-stationary or has a unit root.

\section{Table IV: Auto Regression Models}

\begin{tabular}{lcccc}
\hline \multicolumn{1}{c}{ Index (Market) } & Coef. & T-statistic & Prob. & Durbin-Watson Statistic \\
\hline NIFTY50 (India) & 0.0568 & 1.9971 & 0.0460 & 1.998 \\
\hline IPC Index (Mexico) & 0.1006 & 3.5912 & 0.0003 & 1.985 \\
\hline $\begin{array}{l}\text { Karachi 100 } \\
\text { (Pakistan) }\end{array}$ & 0.1611 & 5.7342 & 0.0000 & 1.985 \\
\hline TASI (Saudi Arabia) & 0.1328 & 4.7299 & 0.0000 & 1.992 \\
\hline BIST 100 (Turkey) & 0.0165 & 0.5859 & 0.5581 & 2.001 \\
\hline EGX100 (Egypt) & 0.2638 & 9.5381 & 0.0000 & 2.009 \\
\hline $\begin{array}{l}\text { IDX Kompas 100 } \\
\text { (Indonesia) }\end{array}$ & 0.0362 & 1.2618 & 0.2072 & 1.996 \\
\hline $\begin{array}{l}\text { Bovespa Brazil 50 } \\
\text { (Brazil) }\end{array}$ & -0.0015 & -0.0541 & 0.9568 & 1.997 \\
\hline SET 100 (Thailand) & 0.0162 & 0.5666 & 0.5711 & 1.994 \\
\hline
\end{tabular}

Note: Table IV presents the results of regression model $Y_{t}=a+b_{y t-1}+E_{t}$ which tests the impact of changes in the previous day's daily returns $\left({ }_{\mathrm{yt}-1}\right)^{\mathrm{t}}$ on the returns of time $t\left(\mathrm{Y}_{\mathrm{t}}\right)$. 
whether market returns movements for one period of time are related to the movements in the previous period. As can be seen from the results, coefficients are positive and highly significant for Mexico, Pakistan, Saudi Arabia and Egypt. This indicates a significant impact of stock returns in one period on stock returns of the next period, thus, supporting the rejection of the random walk. Regarding India, the results show a lower significance level. On the other hand, Turkey, Indonesia, Brazil, and Thailand show insignificant results, thus, showing an insignificant impact of stock returns in one period on the next. These results will further be backed up by the results of the non-parametric run tests.

As provided in Table $\mathrm{V}$, the results of the run tests indicate that five markets (India, Brazil, Thailand, Indonesia, Turkey) show a sign of efficiency. This is evident by a $z$ value in between \pm 1.96 , indicating the failure to reject the null hypothesis that data are random. On the other hand, at the 5 percent significant level, the results for Egypt, Saudi Arabia, Mexico and Pakistan reject the null hypothesis, indicating non randomness of data, hence, inefficiency. These results make sense since the results of the autoregressive models also show that Turkey, Thailand, Indonesia, and Brazil generated insignificant results, and that India had a lower significance level than Egypt, Saudi Arabia, Mexico and Pakistan who had generated

\section{Table V: Run Tests}

\begin{tabular}{|c|c|c|c|c|c|c|c|}
\hline $\begin{array}{c}\text { Index } \\
\text { (Market) }\end{array}$ & $\begin{array}{l}\text { Test value } \\
\text { (Mean) }\end{array}$ & $\begin{array}{l}\text { Cases< } \\
\text { test value }\end{array}$ & $\begin{array}{c}\text { Cases } \geq \\
\text { test value }\end{array}$ & $\begin{array}{l}\text { Total } \\
\text { cases }\end{array}$ & $\begin{array}{c}\mathrm{N} \\
\text { Runs }\end{array}$ & Z & $\begin{array}{c}P \text { - } \\
\text { value }\end{array}$ \\
\hline NIFTY50 (India) & 0.000313 & 609 & 624 & 1233 & 611 & -0.365 & 0.715 \\
\hline $\begin{array}{l}\text { Is IPC Index } \\
\text { (Mexico) }\end{array}$ & 0.000027 & 623 & 632 & 1255 & 591 & -2.116 & 0.034 \\
\hline $\begin{array}{c}\text { Karachi } 100 \\
\text { (Pakistan) }\end{array}$ & 0.000195 & 616 & 623 & 1239 & 495 & -7.133 & 0.000 \\
\hline $\begin{array}{c}\text { TASI } \\
\text { (Saudi Arabia) }\end{array}$ & -0.000005 & 596 & 653 & 1249 & 567 & -3.245 & 0.001 \\
\hline $\begin{array}{l}\text { BIST } 100 \\
\text { (Turkey) }\end{array}$ & 0.000232 & 616 & 640 & 1256 & 650 & 1.199 & 0.231 \\
\hline $\begin{array}{c}\text { EGX100 } \\
\text { (Egypt) }\end{array}$ & 0.000200 & 598 & 620 & 1218 & 531 & -4.519 & 0.000 \\
\hline $\begin{array}{c}\text { IDX Kompas } \\
100 \text { (Indonesia) }\end{array}$ & -0.000087 & 634 & 578 & 1212 & 585 & -1.193 & 0.233 \\
\hline $\begin{array}{c}\text { Bovespa Brazil } \\
50 \text { (Brazil) }\end{array}$ & 0.000668 & 622 & 623 & 1245 & 637 & 0.766 & 0.444 \\
\hline $\begin{array}{c}\text { SET } 100 \\
\text { (Thailand) }\end{array}$ & 0.000057 & 602 & 617 & 1219 & 610 & -0.023 & 0.981 \\
\hline
\end{tabular}

Note: Table $V$ presents the results of the run tests which test the null hypothesis that data are random. highly significant results supporting serial correlation between the time variables.

These results are somehow consistent with the results made by Malafeyev et al. (2017) when they conducted their study on the Chinese and Indian markets and how they may be impacted by both the global financial crisis and the Chinese crisis. As a result of their run tests, they found that the Indian market showed movements towards efficiency in comparison with the Chinese market. This is also coherent with the results generated by Lagoarde-Segot and Lucey (2008) when they found that Turkey and Israel are closer to following random walk then their tested counterparts.

The results of ADF reject random-walk and the weak-form efficiency for all tested indices. While on the other hand, the results of the autoregressive models and run tests show mixed and inconclusive results with regards to whether the daily stock returns in the tested emerging markets follow a random-walk or not. But overall, the null hypothesis of randomness $\mathrm{HOb}$ is rejected, and the alternative is accepted. However, it is very important to note that Turkey, Thailand, Indonesia, Brazil, and India are moving towards attaining weak-form efficiency in comparison with Mexico, Saudi Arabia, Egypt, and Pakistan. This makes sense, since generally with the exception of Mexico, these markets are more developed than their tested counterparts. In an article in the business insider by Burroughs (2019), Turkey, Thailand and India were ranked in the top 10 fastest growing emerging market economies. 


\section{Robustness Check}

As provided by Table VI, the results of the Zivot-Andrews unit root test support the rejection of the null hypothesis in all tested indices either at the $1 \%, 5 \%$ and $10 \%$ with the exception of the EGX100 which failed to reject the null hypothesis of a unit root with one structural break. These results contradict the results of ADF and PP unit root test with regards to the Egyptian market but consistent in all other markets. As provided by the results of the EGX100, the break point is on the $19^{\text {th }}$ of October 2016. This date actually makes sense with regards to certain events happening in the Egyptian market around this time. This may be around the time where anticipations and rumors regarding the free float of the Egyptian pound started spreading in Egypt. The actual floating took place on November $3^{\text {rd }}$ of that same year.

As a recommendation for future research, it may be interesting to further explore the randomness of these markets by applying tests that incorporate more than one structural break in the model. Also, the significance and importance of the break date should be further investigated with regards to each market.

\section{Conclusion}

This study examined the relevance of the efficient market hypothesis in emerging markets by testing the weak-form efficiency in nine emerging markets. The results show that stock markets in the tested emerging markets do not follow a random walk, hence are not weakly efficient. This means that for sure they are not efficient in any other form whether semi-strong or strong. This may be due to weak corporate governance, financial reforms and regulations in many of these countries. Also, the results indicate that these markets may have greater information asymmetries that may lead to more insider trading, higher transaction costs, and weaker investor protection.

However, it is very important to note that the results showed that Turkey, Thailand, Indonesia, Brazil and India may be moving towards attaining weak-form efficiency in comparison with Mexico, Saudi Arabia, Egypt and Pakistan. This indicates that markets in Mexico, Saudi Arabia, Egypt and Pakistan are more predictable and less efficient. It is recommended that further investigations to be done in order to be able to conclusively determine the economic and financial differences that led to this. Also, another recommendation for future research could be to test some of the market anomalies that impact the validity of the efficient market hypothesis, such as, the January effect or the small firm effect. As mentioned earlier, it is recommended to employ further tests that incorporate more than one structural break to further test for unit root.

Overall, the results of this research add to the literature pertaining to the legitimacy of the efficient market hypothesis in emerging markets. Also, the results may be of interest to market regulators in conducting financial reforms to reduce corruption and information asymmetries in an attempt to becoming more efficient. This research may also be of importance to investors who are interested in investing in such emerging markets. 


\section{References}

Alam, M. M.; Alam, K. A. and Uddin, M. G. S. (2007). "Market depth and risk return analysis of Dhaka Stock Exchange: An empirical test of market efficiency", ASA University Review, Vol. 1, No. 1, pp. 93-101.

- $\quad$ Atkan, C.; Sahin, E. E. and Kucukkaplan, I. (2018). “Testing the information efficiency in Emerging Markets", Financial Management from an Emerging Market Perspective, Guray Kucukkocaoglu and Soner Gokten, Intech Open, Available at: http://dx.doi.org/10.5772/intechopen.70369

- $\quad$ Ayentimi, D.T.; Mensah, A. E. and Naa-Idar, F. (2013). "Stock market efficiency of Ghana Stock Exchange: An objective analysis", International Journal of Management, Economics and Social Sciences, Vol. 2, Issue 2, pp. 54-75.

- Burroughs, C. (2019). "These 10 emerging markets will dominate the global economy in the next decade", Business Insider, Available at: https://www.businessinsider.com/oxford-economics-ranking-of-emerging-market-economies-2019-2

- Chaibi, L. F. (2014). "Testing the random walk: The case of Hong Kong Stock Exchange”, Journal of Empirical Studies, Vol. 1, No. 2, pp. 54-61.

- Cooray, A. and Wickremasinghe, G. (2007). "The efficiency of Emerging Stock Markets: Empirical evidence from the South Asian region", The Journal of Developing Areas, Vol. 41, No. 1, pp. 171183.

- Gupta, R. and Yang, J. (2011). “Testing weak form efficiency in the Indian Capital Market", International Research Journal of Finance and Economics, Issue 75, pp. 108-119.

- Howrey, E. P. (1965). "Are stock prices random or predictable?", Business Economics, Vol. 1, No. 1, pp. 21-24.

- Kamel, M. (2014). "Studying the validity of the Efficient Market Hypothesis (EMH) in the Egyptian Exchange (EGX) after the $25^{\text {th }}$ of January Revolution", Munich Personal RePEc Archive (MPRA), Available at: http://mpra.ub.uni-muenchen.de/54708/

- $\quad$ Lagoarde-Segot, T. and Lucey, B. M. (2008). "Efficiency in emerging markets- Evidence from the MENA region", International Financial Markets, Institutions \& Money, Vol. 18, pp. 94-105.

- Malafeyev, O.; Awasthi, A. and Kambekar, K. S. (2017). "Random walks and market efficiency in Chinese and Indian equity markets", arXiv.1709.04059 [q-fin.CP] - arXiv.org

- Mobarek, A. and Keasey, K. (2000). “Weak-form market efficiency of an emerging market: Evidence from Dhaka Stock Market of Bangladesh", ENBS Conference, Oslo, May.

- Nisar, S. and Hanif, M. (2012). “Testing weak form of efficient market hypothesis: Empirical evidence from South-Asia", World Applied Sciences Journal, Vol. 17, No. 4, pp.414-427.

- Nurunnabi, M. (2012). "Testing weak-form efficiency of emerging economies: A critical review of literature", Journal of Business Economics and Management, Vol. 13, No. 1, pp. 167-188.

- Oprean, C. (2012). "Testing the financial market informational efficiency in emerging state", Review of Applied Socio-Economic Research, Vol. 4, Issue 2, pp. 181-190.

- Poshakwale, S. (2002). "The random walk hypothesis in the emerging Indian Stock Market", Journal of Business Finance \& Accounting, Vol. 29, No. 9 \& 10, pp. 1275-1299.

- $\quad$ Simons, D.; Laryea, S. A. (2005). "Testing the efficiency of selected African stock markets", SSRN Electronic Journal: http://dx.doi.org/10.2139/ssrn.874808

- Worthington, A. and Higgs, H. (2004). "Random walks and market efficiency in european equity markets", Global Journal of Finance and Economics, Vol. 1, No. 1, pp. 59-78. 
